\title{
Effects of context preexposure and delay until anxiety retrieval on generalization of contextual anxiety
}

\author{
Marta Andreatta, ${ }^{1}$ Dorothea Neueder, ${ }^{1}$ Evelyn Glotzbach-Schoon, ${ }^{1}$ \\ Andreas Mühlberger, ${ }^{1,2}$ and Paul Pauli ${ }^{1,3}$ \\ ${ }^{1}$ Department of Psychology (Biological Psychology, Clinical Psychology, and Psychotherapy), University of Würzburg, 97070 \\ Würzburg, Germany; ${ }^{2}$ Department of Psychology (Clinical Psychology and Psychotherapy), University of Regensburg, 93053 \\ Regensburg, Germany; ${ }^{3}$ Center of Mental Health, Medical Faculty, University of Würzburg, 97070 Würzburg, Germany
}

\begin{abstract}
Animal studies suggest that time delay between acquisition and retrieval of contextual anxiety increases generalization. Moreover, such generalization is prevented by preexposure to the context (CTX), presumably due to an improved representation of such context. We investigated whether preexposure and time-passing modulate generalization of contextual anxiety, in humans. On Day 1, 42 participants (preexposure group) explored two virtual offices, while 41 participants (no-preexposure group) explored a virtual stadium. On Day 2 (24 h later), all participants learned to associate one office $(\mathrm{CTX}+$ ) with unpredictable unconditioned stimuli (USs), and another office (CTX -) with safety. On Day 3, either $24 \mathrm{~h}$ (recent test) or $2 \mathrm{wk}$ (remote test) later, participants revisited CTX - and CTX + without USs, as well as a generalization context (G-CTX). Results revealed successfully conditioned anxiety and anxiety generalization for ratings (G-CTX was as aversive as CTX + was), while safety generalization was found for startle responses (G-CTX elicited startle attenuation as CTX - did). Time between learning and testing enhanced generalization as reflected by comparable startle responses to all three offices in the remote test. Contextual preexposure facilitated extinction of explicit conditioned anxiety assessed with ratings. These results suggest that memory trace of a context degrades with passage of time in humans like in animals and, consequently, anxiety generalization enhances. After context preexposure, high cognitive processes seem to be crucially involved in facilitating extinction (or safety) learning.
\end{abstract}

[Supplemental material is available for this article.]

Anxiety, in contrast to fear, has no specific easily identifiable trigger. For instance, a person who previously was scared by a dog while being in a park may develop fear of dogs but may also experience anxiety as long as he or she is in the park again, although no dog is visible. Thus, individuals learn an association between an aversive event (i.e., the US) and a specific stimulus (dog, CS+) and/or a context (park, CTX+); the former is commonly called cued (fear) conditioning, and the latter contextual (anxiety) conditioning (for a recent review, see Maren et al. 2013). The main difference between both forms of learning is that context conditioning is when the US cannot be predicted in a reliable and precise manner by a distinct signal, and therefore the person experiences long-lasting anxiety while in the context, which is also called sustained fear response (Davis et al. 2010). In contrast, cued (fear) conditioning is when the US is reliably predicted by a cue and, consequently, such a signal elicits a prompt fear response (called phasic fear), which is of short duration and terminates as soon as the threat or its signal disappears (Davis et al. 2010).

While the behavioral and neural mechanisms of fear or cued fear conditioning are fairly well examined in animal and humans (see Mechias et al. 2010; Fullana et al. 2016), studies on anxiety or contextual conditioning are less frequent and only recently have become the focus of human research (for recent reviews, see Davis et al. 2010; Perusini and Fanselow 2015; Tovote et al. 2015).

Corresponding authors: marta.andreatta@mail.uni-wuerzburg.de or pauli@mail.uni-wuerzburg.de

Article is online at http://www.learnmem.org/cgi/doi/10.1101//m.044073. 116. Freely available online through the Learning \& Memory Open Access option.
Amygdala activation (Marschner et al. 2008; Lang et al. 2009; Andreatta et al. 2015b) and startle potentiation (Grillon et al. 2006; Glotzbach-Schoon et al. 2013a) have been found in both $\mathrm{CS}+$ and CTX+ (the context associated with the US) when compared with CS - or CTX - (the context not associated with the US, i.e., safe). However, a context is much more complex than a discrete cue and due to this complexity, context conditioning requires additional processes and brain structures (Fanselow 2010). Both the amygdala and the hippocampus are mandatory for such contextual conditioning, as demonstrated by animal studies revealing deficits in the acquisition of conditioned anxiety when the hippocampus and/or the amygdala were lesioned before context conditioning (Fanselow 2010; Maren et al. 2013; Bannerman et al. 2014). Corroborating these results, we and others found greater hippocampal activation triggered by CTX + when compared with CTX - (Marschner et al. 2008; Lang et al. 2009; Andreatta et al. 2015b) in humans. The amygdala provides the neuronal underpinnings for the conditioned anxiety response, while the hippocampus seems to encode context-related information (Fanselow 2010) and together with the amygdala fosters the context-US association (Richter-Levin 2004; Maren et al. 2013).

The hippocampus is crucially involved in the formation of spatial (O'Keefe and Dostrovsky 1971; Schiller et al. 2015) and cognitive maps (Rudy 2009; Bannerman et al. 2014), and such processes are likely to be essential for the discrimination between

(C) 2016 Andreatta et al. This article, published in Learning \& Memory, is available under a Creative Commons License (Attribution-NonCommercial 4.0 International), as described at http://creativecommons.org/licenses/by-nc/ $4.0 /$. 
threatening and safety contexts. Moreover, the hippocampus plays a fundamental role in memory processes in general (Squire and Zola-Morgan 1991; Squire 2004). To remember events even years later, the initial short-term memory (STM) has to be transferred into long-term memory (LTM) (Frankland and Bontempi 2005). Such consolidation processes may happen overnight and require a tight interplay between the hippocampus and the medial prefrontal cortex (mPFC). Supportively, participants' memory significantly improved after one night during which the memory trace of the task became reactivated during sleep (Rasch et al. 2007). Once consolidated, the memory becomes hippocampusindependent (Frankland and Bontempi 2005). However, even LTM traces age and individuals cannot recall particulars of that event anymore, or they make new experiences, which may interfere with the original memory. In other words, individuals forget.

One important and clinically relevant question is what happens when fear or anxiety memories age? An interesting review (Riccio et al. 1992) suggested that with time, memory traces weaken and conditioned responses lose differentiation over time. In other words, generalization increases with delay between training and testing. Biedenkapp and Rudy (2007) followed up this idea and manipulated the delay between acquisition and testing. Namely, in a first study, rats underwent a simple context conditioning during which they received one or two painful electric footshocks (US) unpredictably in one cage (Context A). One, 7, or 15 d later, rats were tested either in the training or in an altered context (Context B), which contained only a subset of the features of the training context. Rats tested 1 or $7 \mathrm{~d}$ after conditioning showed greater fear responses (i.e., freezing) to the Context A when compared with Context B, suggesting discriminative fear responses. Interestingly, rats tested $15 \mathrm{~d}$ later showed comparable freezing to both Context A and B. In line with Riccio et al. (1992), Biedenkapp and Rudy (2007) hypothesized that the memory trace of the Context A became weaker through time and rats, forgetting details of Context A, generalized fear to Context B. Importantly, in a second study they succeeded in reducing generalization of contextual fear, i.e., preventing the memory trace to degrade by allowing rats to explore the training cage (Context A) before context conditioning, while a control group explored a completely different context (Context X). The acquisition phase was the same as in Study 1 and then rats were tested either one or $15 \mathrm{~d}$ later in the Context A or Context B. Strikingly, rats that explored Context A before acquisition (preexposure group) did not generalize anxiety to Context B when tested 15 d later, whereas rats that explored Context $\mathrm{X}$ before acquisition exhibited generalization of anxiety as in Study 1. These results suggest that preexposure to a context fosters formation of a memory trace, which after an association with the threat, remains rather stable over time. Thus, such preexposure seems to prevent weakening of the memory trace of contexts and therefore reduces generalization of anxiety.

The translation of such context conditioning studies to humans is not easily achieved. This far, most human studies manipulated contexts by using long-lasting stimuli, e.g., the background color of the computer screen (Kalisch et al. 2006; Pohlack et al. 2012) or pictures of rooms (Marschner et al. 2008; Fonteyne et al. 2010), while a few studies used a real room (LaBar and Phelps 2005). However, the former lack the spatial aspect of a context and the latter is less manipulable and/or controllable. For these reasons, we took advantage of virtual reality (VR) to manipulate contexts for contextual anxiety conditioning to humans. VR is an ecological tool (Sanchez-Vives and Slater 2005) which permits building highly controlled environments and to take into account both temporal and spatial aspects of the context. Furthermore, using VR in humans allows a more direct translation of animal paradigms to humans (Baas et al. 2004; Huff et al. 2011; Glotzbach-Schoon et al. 2013b; Andreatta et al. 2015b).
The present study was designed to investigate the generalization of contextual anxiety in humans and the role of preexposure for preventing generalization, i.e., preventing forgetting. In contrast to the animal studies by Biedenkapp and Rudy (2007), we performed-similar to most previous human context condition studies (e.g., Glotzbach-Schoon et al. 2013b)—a differential contextual conditioning paradigm because this allows us to demonstrate learning by comparing responses to CTX + versus CTX - . On Day 1 (Preexposure Session), half of the participants actively explored two virtual offices (preexposure group), while the other half explored a stadium (no-preexposure group) by means of a joystick. On Day 2 (Acquisition Session), all participants underwent a differential context conditioning protocol during which a painful electric shock (US) was unpredictably delivered in one office (anxiety context or CTX+), but never in the other office (safety context or CTX-). On the final test day (GeneralizationTest Session), participants underwent a test (or extinction) phase during which they were passively guided into CTX + and CTXagain, but no US was delivered. Additionally on this day, participants visited a third novel context (generalization context or G-CTX), which consisted of an equal mix between CTX + and CTX - furniture (see Andreatta et al. 2015b). Importantly, the final test day was for half of the preexposure group and half of the no-preexposure group $24 \mathrm{~h}$ after acquisition (recent test), whereas the other two halves were tested $15 \mathrm{~d}$ later (remote test). As indices for learning and generalization, we collected verbal ratings, startle responses, and skin conductance level (SCL).

First, we expected successful contextual anxiety conditioning reflected in enhanced anxiety responses to CTX + compared with CTX - . Second, we anticipated generalization of anxiety responses especially when tested delayed, i.e., $15 \mathrm{~d}$ after acquisition, indicated by stronger anxiety responses to G-CTX compared with CTX - . Finally, we expected that context preexposure reduces fear generalization when tested $15 \mathrm{~d}$ after acquisition. Specifically, we expected comparable startle responses and anxiety ratings to G-CTX and CTX - in the preexposure group but not in the no-preexposure group.

\section{Results}

We calculated three separated ANOVAs for each day (preexposure session, acquisition session, generalization test session; see Materials and Methods). For clarity, we present the effects following our hypothesis. We first describe the effect of conditioned anxiety (i.e., the main and interaction effects of context and phase for the Acquisition Session); second, the effects for generalization of conditioned anxiety (i.e., the main and interaction effects of context and phase for the Generalization-Test Session); third, the effects of time-passing (i.e., the main and interaction effects involving the factor test-delay for the Generalization-Test Session); and fourth, the effects of preexposure (i.e., the main and interaction effects involving the factor preexposure group for the Acquisition Session and the Generalization-Test Session).

\section{Context conditioning effects (acquisition session)}

\section{Valence ratings}

Successful context conditioning was reflected in the significant main effects of context $\left(F_{(1,81)}=23.80, P<0.001, \eta_{p}^{2}=0.227\right)$ and phase $\left(F_{(1,81)}=8.24, P=0.005, \eta_{\mathrm{p}}^{2}=0.092\right)$, and a significant Context $\times$ Phase interaction $\left(F_{(1,81)}=11.57, P=0.001\right.$, $\eta_{\mathrm{p}}^{2}=0.125$ ) (Fig. 1A). Post hoc simple contrasts indicated that the anxiety compared with the safety context was rated as more negatively valenced after Acquisition $1\left(F_{(1,81)}=10.35, \quad P=\right.$ $\left.0.002, \eta_{\mathrm{p}}^{2}=0.113\right)$ as well as after Acquisition $2\left(F_{(1,81)}=31.45\right.$, 

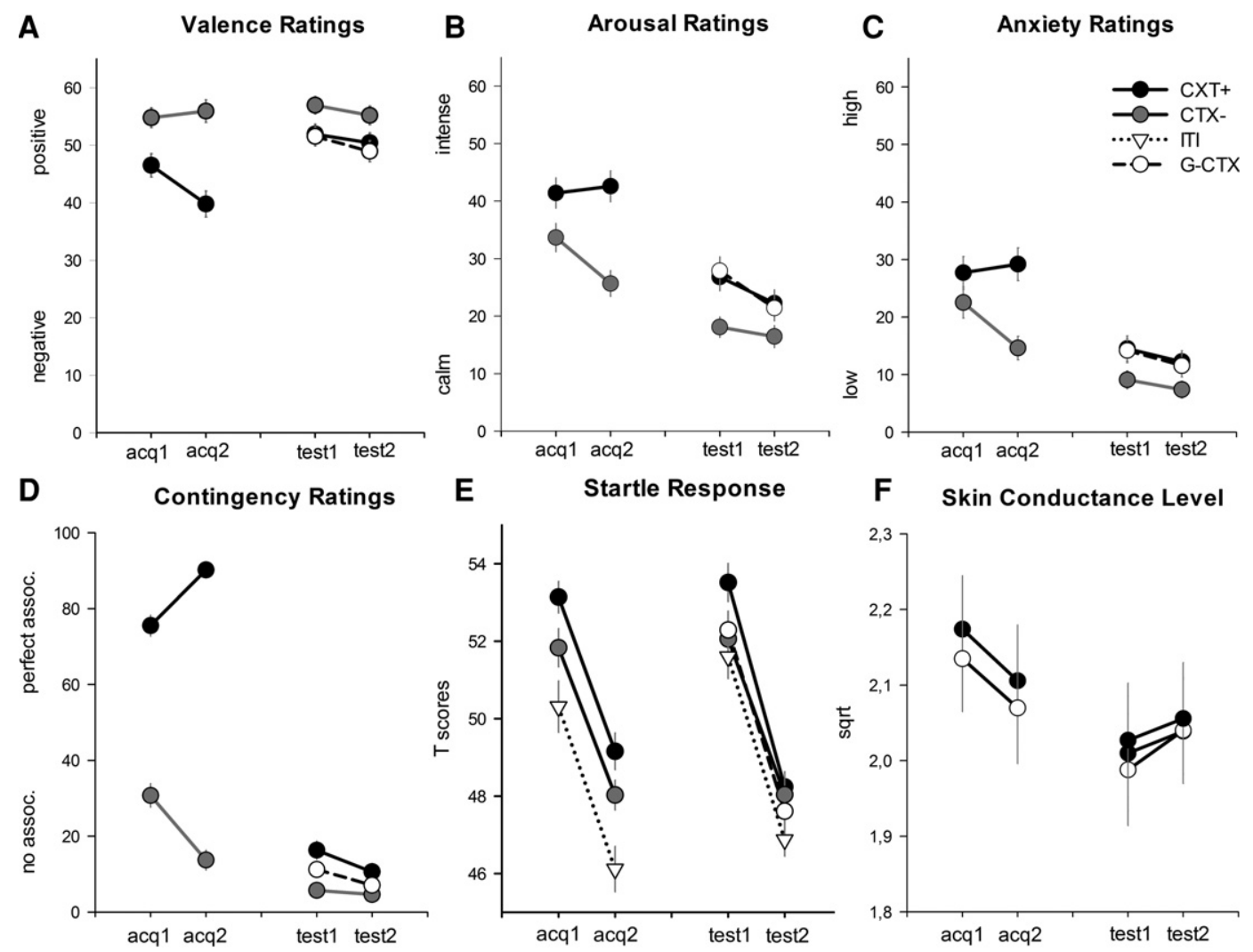

Figure 1. Depicted are $(A)$ valence ratings, $(B)$ arousal rating, $(C)$ anxiety ratings, $(D)$ contingency ratings, $(E)$ startle response, and $(F)$ skin conductance level (SCL). Lines (with standard errors) indicate the responses to the anxiety context (CTX+, black lines), the safety context (CTX-, gray lines) and the generalization context (G-CTX, black dotted lines) after (for the ratings) and during (for the physiological responses) the first acquisition phase (Acq1), the second acquisition phase (Acq2), the first generalization phase (Gen1), and the second generalization phase (Gen2). Black dashed lines depict the startle responses during the intertrial interval (ITI). Analysis for the acquisition session revealed that participants rated CTX + more $(A)$ negative, $(B)$ arousing, and (C) anxiogenic than CTX - . Moreover, participants $(D)$ expected the US more in CTX + than in CTX - and responded with $(E)$ enhanced startle response and $(F)$ larger SCL to CTX + compared with CTX - . In the test phase, generalization of contextual fear was found on the explicit level of responses, that is G-CTX was rated as $(A)$ negative, $(B)$ arousing, and $(C)$ axiogenic as CTX + . On the implicit level, we found generalization of contextual safety as indicated by $(F)$ lower startle responses to $\mathrm{G}-\mathrm{CTX}$ than to $\mathrm{CTX}+$. Interestingly, $(E)$ the G-CTX elicited a higher SCL than the other two rooms.

$\left.P<0.001, \eta_{\mathrm{p}}^{2}=0.280\right)$. Also, the negative valence of the anxiety context increased from Acquisition 1 to Acquisition $2\left(F_{(1,81)}=\right.$ $\left.19.96, P<0.001, \eta_{\mathrm{p}}^{2}=0.198\right)$, while the valence of the safety context did not change $\left(F_{(1,81)}=0.39, P=0.532, \eta_{\mathrm{p}}^{2}=0.005\right)$.

\section{Arousal ratings}

Analysis revealed a significant main effect for the context $\left(F_{(1,81)}=44.76, \quad P<0.001, \eta_{\mathrm{p}}^{2}=0.356\right)$, while phase $\left(F_{(1,81)}=\right.$ 3.76, $\left.P=0.056, \eta_{\mathrm{p}}^{2}=0.044\right)$ just failed to reach the significance level. Moreover, the Context $\times$ Phase interaction turned out to be significant $\left(F_{(1,81)}=12.94, P=0.001, \eta_{\mathrm{p}}^{2}=0.138\right.$; Fig. $\left.1 \mathrm{~B}\right)$. Post hoc tests for this interaction indicated that participants rated the anxiety context as more arousing than the safety context after both Acquisition $1\left(F_{(1,81)}=11.67, P=0.001, \eta_{\mathrm{p}}^{2}=0.126\right)$ and Acquisition $2\left(F_{(1,81)}=59.23, P<0.001, \eta_{\mathrm{p}}^{2}=0.422\right)$. Moreover, arousal ratings did not change from Acquisition 1 to Acquisition 2 for the anxiety context $\left(F_{(1,81)}=0.22, P=0.639, \eta_{\mathrm{p}}^{2}=0.003\right)$, whereas they were significantly decreased for the safety context $\left(F_{(1,81)}=17.36, P<0.001, \eta_{\mathrm{p}}^{2}=0.177\right)$.

\section{Anxiety ratings}

Analysis revealed significant main effects of context $\left(F_{(1,81)}=\right.$ 28.57, $\left.P<0.001, \eta_{\mathrm{p}}^{2}=0.261\right)$ and phase $\left(F_{(1,81)}=5.30, P=0.024\right.$, $\left.\eta_{\mathrm{p}}^{2}=0.149\right)$ as well as their interaction $\left(F_{(1,81)}=14.23, P<\right.$ $0.001, \eta_{\mathrm{p}}^{2}=0.149$; Fig. 1C). Post hoc contrasts for the interaction indicated that participants reported a higher level of anxiety in the anxiety than the safety context after both Acquisition 1 $\left(F_{(1,81)}=6.33, P=0.014, \eta_{\mathrm{p}}^{2}=0.073\right)$ and Acquisition $2\left(F_{(1,81)}=\right.$ 41.94, $\left.P<0.001, \eta_{\mathrm{p}}^{2}=0.341\right)$. Moreover, anxiety ratings did not change from Acquisition 1 to Acquisition 2 for the anxiety context $\left(F_{(1,81)}=0.44, P=0.511, \eta_{\mathrm{p}}^{2}=0.005\right)$, whereas they significantly decreased for the safety context $\left(F_{(1,81)}=15.53, P<\right.$ $\left.0.001, \eta_{\mathrm{p}}^{2}=0.161\right)$.

\section{Contingency ratings}

Analysis revealed significant main effects of context $\left(F_{(1,81)}=\right.$ 287.57, $\left.P<0.001, \eta_{\mathrm{p}}^{2}=0.780\right)$ and a significant interaction Context $\times$ Phase $\left(F_{(1,81)}=43.70, P<0.001, \eta_{\mathrm{p}}^{2}=0.350\right.$; Fig. 1D). Higher US-CTX + compared with US-CTX - contingency ratings were reported after both Acquisition $1\left(F_{(1,81)}=89.14, P<\right.$ $\left.0.001, \eta_{\mathrm{p}}^{2}=0.524\right)$ and Acquisition $2\left(F_{(1,81)}=414.00, P<0.001\right.$, $\left.\eta_{\mathrm{p}}^{2}=0.836\right)$. Moreover, participants reported after Acquisition 2 compared with Acquisition 1 higher association between US and CTX $+\left(F_{(1,81)}=26.76, P<0.001, \eta_{\mathrm{p}}^{2}=0.248\right)$ and in parallel lower association between US and CTX $-\left(F_{(1,81)}=28.20, P<0.001\right.$, $\left.\eta_{\mathrm{p}}^{2}=0.258\right)$. 


\section{Startle response}

Analysis showed significant main effects for context $\left(F_{(2,162)}=\right.$ 14.14, GG- $\varepsilon=0.870, P<0.001, \eta_{\mathrm{p}}^{2}=0.149$; Fig. $\left.1 \mathrm{E}\right)$ and phase $\left(F_{(1,81)}=49.13, P<0.001, \eta_{\mathrm{p}}^{2}=0.378\right)$, but not for their interaction $\left(F_{(2,162)}=0.09, \mathrm{GG}-\varepsilon=0.914, P=0.899, \eta_{\mathrm{p}}^{2}=0.001\right)$. Post hoc tests for the main context effect indicated significant startle potentiation to CTX + compared with CTX $-\left(F_{(1,81)}=7.88, P=\right.$ $\left.0.019, \eta_{\mathrm{p}}^{2}=0.089\right)$ and the ITI $\left(F_{(1,81)}=23.87, \quad P<0.001\right.$, $\left.\eta_{\mathrm{p}}^{2}=0.228\right)$. Startle magnitude was also significantly larger to the CTX - when compared with the ITI $\left(F_{(1,81)}=7.89, P=\right.$ $\left.0.019, \eta_{\mathrm{p}}^{2}=0.089\right)$. The main effect phase indicates significantly lower startle magnitude during Acquisition 2 than Acquisition 1.

\section{Skin conductance level (SCL)}

There were significant main effects of context $\left(F_{(1,75)}=41.38\right.$, $\left.P<0.001, \eta_{\mathrm{p}}^{2}=0.356\right)$, which indicated higher SCL in CTX+ compared with CTX-, and phase $\left(F_{(1,75)}=11.03, P=0.001\right.$, $\eta_{\mathrm{p}}^{2}=0.128$ ), with lower SCL during Acquisition 2 compared with Acquisition 1, possibly related to habituation (Fig. 1F). The interaction Context $\times$ Phase did not reach significance $\left(F_{(1,75)}=0.07, P=0.791, \eta_{\mathrm{p}}^{2}=0.001\right)$.

\section{Generalization effects (generalization-test session)}

\section{Valence ratings}

The ANOVA returned significant main effects of context $\left(F_{(2,158)}=\right.$ 6.70, GG- $\varepsilon=0.925, P=0.002, \eta_{\mathrm{p}}^{2}=0.078$; Fig. 1A) and phase $\left(F_{(1,79)}=5.42, P=0.022, \eta_{\mathrm{p}}^{2}=0.064\right)$. Post hoc tests indicated generalization of anxiety since the participants rated both CTX+ $\left(F_{(1,79)}=6.67, P=0.035, \eta_{\mathrm{p}}^{2}=0.078\right)$ and G-CTX $\left(F_{(1,79)}=11.24\right.$, $\left.P=0.004, \eta_{\mathrm{p}}^{2}=0.125\right)$ as more negative than CTX - , while G-CTX was rated as negative as CTX $+\left(F_{(1,79)}=0.40, P=0.395\right.$, $\left.\eta_{\mathrm{p}}^{2}=0.005\right)$. The interaction between context and phase was not significant $\left(F_{(2,158)}=0.33, P=0.719, \eta_{\mathrm{p}}^{2}=0.004\right)$.

\section{Arousal ratings}

The main effects context $\left(F_{(2,158)}=16.41, P<0.001, \eta_{\mathrm{p}}^{2}=0.172\right)$ and phase $\left(F_{(1,79)}=9.15, P=0.003, \eta_{\mathrm{p}}^{2}=0.104\right)$ turned out to be significant, as well as the interaction Context $\times$ Phase $\left(F_{(2,158)}=\right.$ 2.92, $P=0.022, \eta_{\mathrm{p}}^{2}=0.047$; Fig. 1B). Post hoc tests for the significant interaction indicated that both CTX+ and G-CTX were rated more arousing than $\mathrm{CTX}-$ after Test $1\left(\mathrm{CTX}+: F_{(1,79)}=\right.$ 19.80, $P<0.001, \eta_{\mathrm{p}}^{2}=0.200$; G-CTX: $F_{(1,79)}=33.46, P<0.001$, $\left.\eta_{\mathrm{p}}^{2}=0.298\right)$ as well as after Test $2\left(\mathrm{CTX}+: F_{(1,79)}=13.27, P=\right.$ $0.001, \eta_{\mathrm{p}}^{2}=0.144$; G-CTX: $\left.F_{(1,79)}=13.46, P=0.001, \eta_{\mathrm{p}}^{2}=0.146\right)$. No differences were found between CTX + and G-CTX after both Test $1\left(F_{(1,79)}=0.30, P=0.587, \eta_{\mathrm{p}}^{2}=0.00\right)$ and Test $2\left(F_{(1,79)}=\right.$ $\left.0.30, P=0.589, \eta_{\mathrm{p}}^{2}=0.004\right)$.

\section{Anxiety ratings}

Analysis indicated significant main effects of context $\left(F_{(2,158)}=\right.$ 13.76, $P<0.001, \eta_{\mathrm{p}}^{2}=0.148$; Fig. $\left.1 \mathrm{C}\right)$ and phase $\left(F_{(1,79)}=5.20\right.$, $\left.P=0.025, \eta_{\mathrm{p}}^{2}=0.062\right)$, but not their interaction $\left(F_{(2,158)}=0.22\right.$, $\left.\mathrm{GG}-\varepsilon=0.924, P=0.784, \eta_{\mathrm{p}}^{2}=0.003\right)$. The main effect phase indicated significant lower anxiety ratings after Test 2 when compared with Test 1 . Post hoc contrasts for the main effect context indicated significantly higher anxiety ratings for both CTX+ $\left(F_{(1,79)}=18.71, \quad P<0.001, \quad \eta_{\mathrm{p}}^{2}=0.191\right)$ and G-CTX $\left(F_{(1,79)}=\right.$ 18.97, $\left.P<0.001, \eta_{\mathrm{p}}^{2}=0.194\right)$ compared with CTX - , while CTX + and G-CTX did not differ $\left(F_{(1,79)}=0.27, P=0.606\right.$, $\left.\eta_{\mathrm{p}}^{2}=0.003\right)$.

\section{Contingency ratings}

We found significant main effects of context $\left(F_{(2,158)}=18.49\right.$, GG- $\left.\varepsilon=0.905, P<0.001, \eta_{\mathrm{p}}^{2}=0.190\right)$ and phase $\left(F_{(1,79)}=6.24\right.$, $\left.P=0.015, \eta_{\mathrm{p}}^{2}=0.073\right)$ and their interaction $\left(F_{(2,158)}=3.26\right.$, $\mathrm{GG}-\varepsilon=0.912, P=0.046, \eta_{\mathrm{p}}^{2}=0.040$; Fig. 1D). Post hoc tests indicated significantly higher contingency ratings for CTX+, compared with CTX - and G-CTX for both Test 1 (CTX-: $F_{(1,79)}=21.60, P<0.001, \eta_{\mathrm{p}}^{2}=0.215$; G-CTX: $F_{(1,79)}=9.14, P=$ $\left.0.010, \eta_{\mathrm{p}}^{2}=0.104\right)$ and Test $2\left(\mathrm{CTX}-: F_{(1,79)}=18.62, P<0.001\right.$, $\eta_{\mathrm{p}}^{2}=0.191 ; \quad$ G-CTX: $\left.\quad F_{(1,79)}=6.18, \quad P=0.045, \quad \eta_{\mathrm{p}}^{2}=0.073\right)$. Interestingly, participants reported a higher probability to receive the US in G-CTX than in CTX - after Test $1\left(F_{(1,79)}=9.33, P=\right.$ $\left.0.009, \eta_{\mathrm{p}}^{2}=0.106\right)$ and (although marginal) still after Test 2 $\left(F_{(1,79)}=5.58, P=0.062, \eta_{\mathrm{p}}^{2}=0.066\right)$.

\section{Startle response}

Analysis revealed significant main effects context $\left(F_{(3,237)}=3.78\right.$, $P=0.011, \eta_{\mathrm{p}}^{2}=0.046$; Fig. $\left.1 \mathrm{E}\right)$ and phase $\left(F_{(1,79)}=153.72, P<\right.$ $\left.0.001, \eta_{\mathrm{p}}^{2}=0.661\right)$, but not their interaction $\left(F_{(3,237)}=0.55\right.$, $\left.P=0.650, \eta_{\mathrm{p}}^{2}=0.007\right)$. Post hoc tests for the main effect context revealed a significant startle potentiation to CTX + when compared with ITI $\left(F_{(1,79)}=8.83, P=0.024, \eta_{\mathrm{p}}^{2}=0.101\right)$ and no other significant differences (all $P \mathrm{~s}>0.187$ ). Therefore, participants showed fear responses to the anxiety context, but safety-like responses to the safety context and to the G-CTX, which suggests generalization of safety.

\section{Skin conductance level $(\mathrm{SCL})$}

Analysis returned a significant main effect of context $\left(F_{(2,144)}=\right.$ 3.38 , GG- $\varepsilon=0.856, P=0.045, \eta_{\mathrm{p}}^{2}=0.045$; Fig. $\left.1 F\right)$, but no phase or interaction effects (all Ps $>0.218$ ). Post hoc tests indicated higher SCL to G-CTX when compared with CTX- $\left(F_{(1,72)}=\right.$ 4.70, $\left.P=0.034, \eta_{\mathrm{p}}^{2}=0.061\right)$, which however did not remain significant after Bonferroni correction $(P=0.101)$. No differences were found between G-CTX and CTX $+\left(F_{(1,72)}=3.14, P=0.242\right.$, $\left.\eta_{\mathrm{p}}^{2}=0.042\right)$ and between CTX + and CTX $-\left(F_{(1,72)}=1.23, P=\right.$ $\left.0.814, \eta_{\mathrm{p}}^{2}=0.017\right)$.

\section{Delay effects (generalization-test session, recent versus remote)}

We found no significant effects involving the factor test-delay for valence (all Ps $>0.118$ ), arousal (all Ps $>0.161$ ), and contingency (all $P \mathrm{~s}>0.064$ ) ratings, meaning that ratings were not influenced by the delay between acquisition and generalization (recent versus remote test). For the anxiety ratings, we found a significant Phase $\times$ Test-Delay interaction $\left(F_{(1,79)}=\right.$ 7.48, $P=0.008, \eta_{\mathrm{p}}^{2}=0.087$ ), but no other effects (all Ps $>$ 0.369). Since this effect did not involve the factor context, we refer the reader to the Supplemental material for further discussion.

The main effect test-delay for the startle response $\left(F_{(1,79)}=\right.$ 2.94, $\left.P=0.090, \eta_{\mathrm{p}}^{2}=0.036\right)$ and the interaction Context $x$ Test-Delay for the SCL $\left(F_{(2,144)}=2.66\right.$, GG- $\varepsilon=0.856, P=0.082$, $\left.\eta_{\mathrm{p}}^{2}=0.036\right)$ just failed to reach the significance level, and all other effects involving the factor test-delay were nonsignificant (Startle response: all $P$ s $>0.491$; SCL: all $P$ s $>0.229$ ).

Considering that we hypothesized an effect of delay on generalization processes, we split the sample according to the testdelay (recent versus remote) and calculated two separate ANOVAs with the between-subjects factor, preexposure group (preexposure, no-preexposure), and within-subjects factors, context $(\mathrm{CTX}+, \mathrm{CTX}-, \mathrm{G}-\mathrm{CTX})$ and phase (Test 1, Test 2). For startle responses (see Fig. 2A), we found significant main effects for context 
A

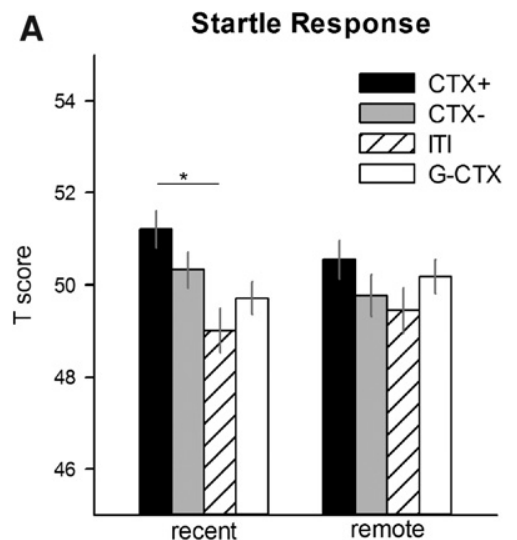

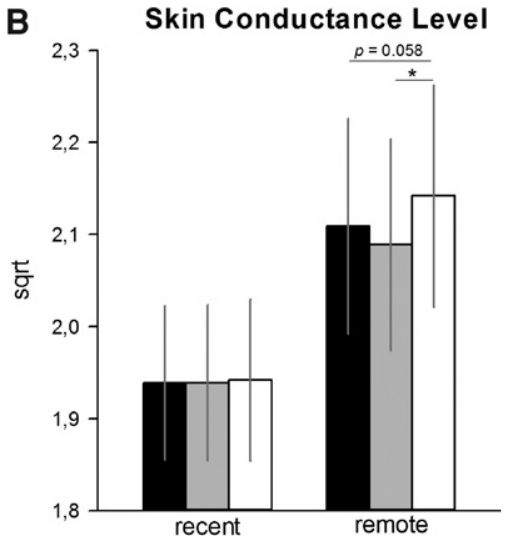

B

Figure 2. (A) Startle responses and (B) skin conductance level $(\mathrm{SCL})$ during the generalization test phase separated for individuals tested $24 \mathrm{~h}$ (recent) or $2 \mathrm{wk}$ (remote) after acquisition. Bars (with standard errors) depict the responses to CTX+ (black), CTX - (gray), G-CTX (white), and IT (striped, only for the startle response). Startle and skin conductance responses suggest successful extinction learning for participants of both the recent test and remote-test group as indicated by comparable responses to CTX + and CTX - . Importantly, the recent test group only tested $24 \mathrm{~h}$ after acquisition was able to distinguish between CTX + and G-CTX, as indicated by differential fear responses (i.e., startle potentiation). Such discrimination was not apparent in the participants tested $15 \mathrm{~d}$ after acquisition, suggesting forgetting of context-threat associations. For further details see text. (*) $P<0.05$.

$\left(F_{(3,123)}=3.84, P=0.011, \eta_{\mathrm{p}}^{2}=0.086\right)$ and phase $\left(F_{(1,41)}=85.29\right.$, $\left.P<0.001, \quad \eta_{\mathrm{p}}^{2}=0.675\right)$ for the recent-test group only. Participants who underwent the generalization test $24 \mathrm{~h}$ after the acquisition phase showed startle potentiation to CTX+ when compared with ITI $\left(F_{(1,41)}=6.02, P=0.043, \eta_{\mathrm{p}}^{2}=0.164\right)$, but not with G-CTX $\left(F_{(1,41)}=6.89, P=0.073, \eta_{p}^{2}=0.144\right)$ or CTX $-\left(F_{(1,41)}=1.81, P=0.186, \eta_{\mathrm{p}}^{2}=0.042\right)$, suggesting discriminative responses. Startle responses to ITI, CTX - , and G-CTX were comparable (all $P \mathrm{~s}>0.076$ ). In contrast, participants who were tested $15 \mathrm{~d}$ after acquisition showed comparable responses to all contexts (main effect context: $F_{(3,114)}=0.90, P=0.446$, $\eta_{\mathrm{p}}^{2}=0.023$; or interaction effects: all $P$ s $\left.>0.340\right)$ and habituation of startle responses from Test 1 to Test 2 (main effect of phase: $\left.F_{(1,38)}=69.20, P<0.001, \eta_{p}^{2}=0.646\right)$. For skin conductance level (SCL) (see Fig. 2B) the ANOVAs revealed no significant effects for the recent-test group (all Ps $>0.209$ ), while, for the remote-test group, we found a significant main context effect $\left(F_{(2,68)}=5.27\right.$, $\left.\mathrm{GG}-\varepsilon=0.708, P=0.016, \eta_{\mathrm{p}}^{2}=0.134\right)$. Only participants, who underwent the remote test, presented significant higher SCL to G-CXT when compared with CTX $-\left(F_{(1,34)}=6.32, P=0.050\right.$, $\left.\eta_{\mathrm{p}}^{2}=0.157\right)$ and marginally to CTX $+\left(F_{(1,34)}=6.04, P=0.058\right.$, $\left.\eta_{\mathrm{p}}^{2}=0.151\right)$ while there was no difference in the SCL between CTX + and CTX $-\left(F_{(1,34)}=2.19, P=0.444, \eta_{\mathrm{p}}^{2}=0.061\right)$.

\section{Preexposure effects}

\section{Valence ratings}

Interestingly, the interaction Context $x$ Preexposure Group turns out to be significant in the Acquisition Session $\left(F_{(1,81)}=\right.$ 6.38, $\left.P=0.014, \eta_{\mathrm{p}}^{2}=0.073\right)$ but just failed significance in the Generalization-Test Session $\left(F_{(2,158)}=2.99\right.$, GG- $\varepsilon=0.925, P=$ $\left.0.057, \eta_{\mathrm{p}}^{2}=0.037\right)$. Accordingly, context preexposure worsened context conditioning (see Fig. 3; Supplemental Fig. S3A) and generalization, but facilitated context extinction (Fig. 4A). In detail, in the Acquisition Session CTX + compared with CTX - was rated as more negatively valenced by the no-preexposure group $\left(F_{(1,40)}=35.58, P<0.001, \eta_{\mathrm{p}}^{2}=0.471\right)$, but not by the preexposure group $\left(F_{(1,41)}=2.27, P=0.139, \eta_{\mathrm{p}}^{2}=0.053\right)$. Moreover, the no-preexposure group rated the safety context significantly group turn out to be significant (all

more positive than the preexposure group $\quad\left(F_{(1,81)}=6.59, \quad P=0.012\right.$, $\left.\eta_{\mathrm{p}}^{2}=0.075\right)$, while both groups did not differ in their valence ratings for the anxiety context $\left(F_{(1,81)}=1.11, P=0.295\right.$, $\left.\eta_{\mathrm{p}}^{2}=0.014\right)$. Thus, preexposure ameliorated conditioning effects.

In the Generalization-Test Session, we (Fig. 4A) observed that participants in the no-preexposure group rated both CTX $+\left(F_{(1,39)}=8.81, \quad P=0.015\right.$, $\left.\eta_{\mathrm{p}}^{2}=0.184\right)$ and G-CTX $\left(F_{(1,39)}=6.53\right.$, $\left.P=0.044, \eta_{\mathrm{p}}^{2}=0.143\right)$ more negative than CTX -, and G-CTX as negative as CTX $\quad\left(F_{(1,39)}=2.13, \quad P=0.134\right.$, $\left.\eta_{\mathrm{p}}^{2}=0.052\right)$. In contrast, participants preexposed to the acquisition contexts rated the three contexts with equal valence (all $P$ s $>0.091$ ). Thus, preexposure somehow enhanced generalization effects.

\section{Arousal ratings}

On the Acquisition Session, no significant main effects or interaction effects involving the factor preexposure Ps $>0.251$ ) (see also Supplemental Fig. S3B). On the contrary, on the Generalization-Test Session the main effect preexposure group $\left(F_{(1,79)}=4.24, P=0.043, \eta_{\mathrm{p}}^{2}=0.051\right)$ and the interaction Context $\times$ Preexposure Group $\left(F_{(2,158)}=5.91, \quad P=0.003\right.$, $\eta_{\mathrm{p}}^{2}=0.070$ ) (Fig. 4B) were significant. Post hoc tests for the Context $\times$ Preexposure-Group interaction revealed significantly higher arousal ratings for CTX + for CTX $-\left(F_{(1,39)}=20.55, P<\right.$ $\left.0.001, \eta_{\mathrm{p}}^{2}=0.345\right)$, but not for G-CTX $\left(F_{(1,39)}=4.99, P=0.094\right.$, $\left.\eta_{\mathrm{p}}^{2}=0.113\right)$ in the no-preexposure group. Moreover, this group reported higher arousal for G-CTX when compared with CTX$\left(F_{(1,39)}=18.03, P<0.001, \eta_{\mathrm{p}}^{2}=0.316\right)$. In parallel to the valence ratings, arousal ratings of the preexposure group were significantly higher for G-CTX than for CTX $-\left(F_{(1,40)}=17.07, P=\right.$ $\left.0.001, \eta_{\mathrm{p}}^{2}=0.299\right)$, but not for CTX $+\left(F_{(1,40)}=4.62, P=0.113\right.$, $\left.\eta_{\mathrm{p}}^{2}=0.104\right)$, while no significant difference was revealed between

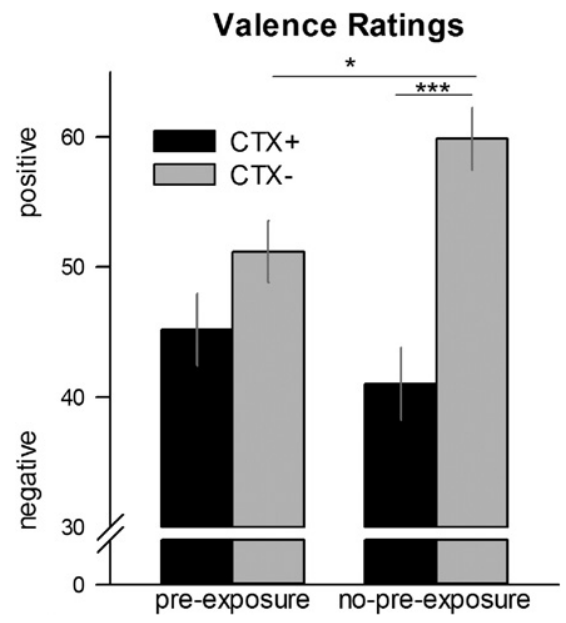

Figure 3. Valence ratings for CTX+ (black lines with standard errors) and CTX - (gray lines with standard errors) after the acquisition phase separated for the no-preexposure (left) and the preexposure (right) group. The preexposure group exhibited less distinction between CTX+ and CTX - than the no-preexposure group. $\left({ }^{*}\right) P<0.05 ;\left({ }^{* * *}\right) P<0.001$. 


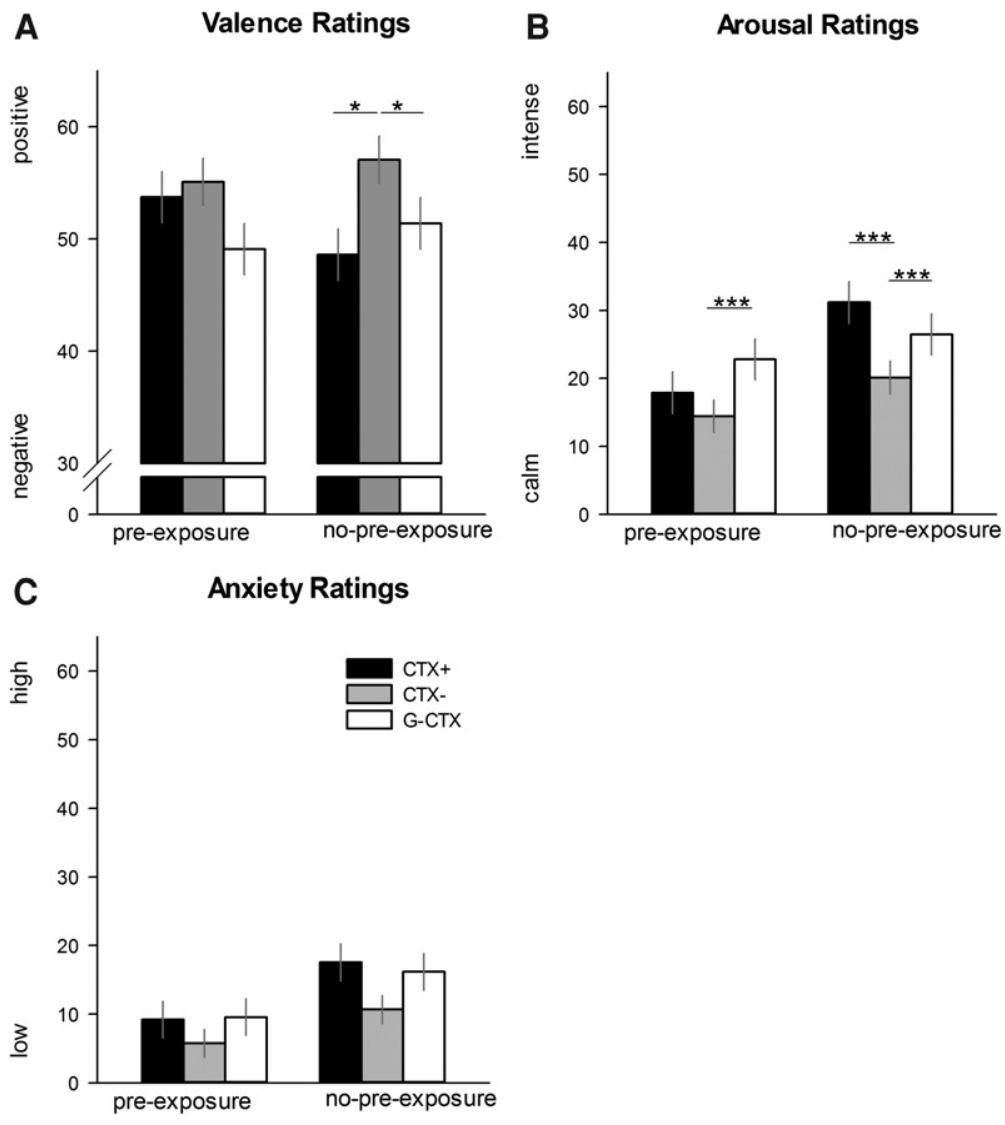

Figure 4. Bars (with standard errors) depict the $(A)$ valence, $(B)$ arousal, and $(C)$ anxiety ratings after the two generalization phases. Participants preexposed to the learning contexts (preexposure group) rated the CTX + (black bars) equally to CTX - (gray bars) and less negative and less arousing than G-CTX (white bars). On the contrary, participants, who were not preexposed to the learning contexts (no-preexposure group) showed differential responses to CTX + versus CTX - and stronger generalization. $\left(^{*}\right) P<0.05 ;\left({ }^{* * *}\right) P>0.001$.

CTX + and CTX $-\left(F_{(1,40)}=2.89, P=0.291, \eta_{\mathrm{p}}^{2}=0.067\right)$. Again, preexposure enhanced generalization

\section{Anxiety ratings}

As for the arousal ratings, no main $\left(F_{(1,81)}=1.36, P=0.247\right.$, $\eta_{\mathrm{p}}^{2}=0.016$ ) or interaction effects (all $P \mathrm{~s}>0.100$ ) (see Supplemental Fig. S3C) involving the factor preexposure group were found on the Acquisition Session. On the GeneralizationTest Session, the main factor preexposure group $\left(F_{(1,79)}=3.98\right.$, $P=0.050, \eta_{\mathrm{p}}^{2}=0.048$ ) (Fig. 4C) turned out to be significant, indicating higher anxiety ratings for the no-preexposure group compared with the preexposed group, but no other effects were revealed (all $P$ s $>0.285$ ).

\section{Contingency ratings}

No significant main or interaction effects involving the factor preexposure group were found on both the Acquisition Session (all Ps > 0.269) and the Generalization-Test Session (all Ps > 0.195). For effects of preexposure on contingency ratings see Supplemental Figure S2D.

No significant effects involving the factor preexposure group were found for the physiological responses on the Acquisition Session (startle response all Ps $>0.264$; SCL: all Ps $>0.125$ ) and the Generalization-Test Session (Startle Responses: all Ps $>$ 0.472; SCL: all Ps $>0.242$ ). For the effect of preexposure on the startle responses and SCL see Supplemental Figure S2E and F, respectively.

\section{Memory test}

Analysis revealed significant main effects of objects $\left(F_{(1,78)}=103.63, \quad P<0.001\right.$, $\left.\eta_{\mathrm{p}}^{2}=0.571\right)$, preexposure group $\left(F_{(1,78)}=\right.$ 20.19, $\left.\quad P<0.001, \quad \eta_{\mathrm{p}}^{2}=0.206\right)$, and test-delay $\quad\left(F_{(1,78)}=16.27, \quad P<0.001\right.$, $\left.\eta_{\mathrm{p}}^{2}=0.173\right)$, but no interaction effects (all $P$ s $>0.149$ ). The main effects indicate that the big objects were better remembered than the small ones, that the preexposure group remembered the objects better than the no-preexposure group, and that the individuals tested 1 $\mathrm{d}$ after the acquisition session remembered more objects than those individuals tested 15 d later. For more details, see Table 1.

\section{Discussion}

According to studies in rodents (Riccio et al. 1992; Biedenkapp and Rudy 2007), contextual anxiety generalization is stronger, when there is a longer delay until anxiety memory retrieval. Specifically, rats tested $15 \mathrm{~d}$ after simple context conditioning generalized their anxiety (i.e., stronger freezing) to a novel context, which shared some characteristics with the threat-associated one, while rats tested after $1 \mathrm{~d}$ after acquisition did not. The authors explain these findings with a weakening of memory traces as time passes. Strikingly, the authors could prevent such anxiety generalization in rats by letting the animals explore the training context before learning. They claim that such preexposure allows the rats to form a more stable representation of the context, which is less susceptible to a time-related decay and thus prevents anxiety generalization even several weeks after acquisition.

We addressed comparable research questions in humans; however, we used a differential context anxiety conditioning protocol (see e.g., Glotzbach-Schoon et al. 2013b). Our first goal was to investigate what happens with regard to retrieval and generalization when anxiety memories age in humans. The second goal was to verify whether preexposure to the training context prevents generalization in humans too. These research questions were addressed on the basis of a differential context anxiety conditioning paradigm using virtual reality to manipulate contexts; in this case, offices (see Tröger et al. 2012; Glotzbach-Schoon et al. 2013a). After preexposure to either the two training contexts (preexposure group) or an irrelevant context (i.e., stadium, no-preexposure group), participants during acquisition received one to three painful electric shocks (i.e., the aversive US) in one office (anxiety context or CTX+), but never in the other one (safety context or CTX-). Anxiety memory and generalization were then tested either $24 \mathrm{~h}$ (recent test) or $15 \mathrm{~d}$ (remote test) after acquisition. During this test, participants revisited the anxiety and the safety contexts, both without US delivery, and a third generalization context (G-CTX), which shared some furniture with both CTX+ and CTX -. 
Generalization of contextual anxiety

Table 1. Numbers (with standard deviation) of the big and small objects correctly located inside the anxiety and safety contexts on Generalization-Test Session before the experiment

\begin{tabular}{|c|c|c|c|c|c|}
\hline & \multicolumn{2}{|c|}{ Preexposure group } & \multicolumn{3}{|c|}{ No-preexposure group } \\
\hline & $\begin{array}{c}\text { Recent } \\
\text { generalization-test }\end{array}$ & $\begin{array}{c}\text { Remote } \\
\text { generalization-test }\end{array}$ & $\begin{array}{c}\text { Recent } \\
\text { generalization-test }\end{array}$ & $\begin{array}{c}\text { Remote } \\
\text { generalization-test }\end{array}$ & Tot. objects \\
\hline \multicolumn{6}{|l|}{ Anxiety context } \\
\hline Big objects & $3.91(1.31)$ & $3.22(1.52)$ & $3.45(1.70)$ & $1.71(1.27)$ & \\
\hline Small objects & $2.39(1.97)$ & $1.56(1.15)$ & $1.65(1.39)$ & $0.95(0.97)$ & \\
\hline \multicolumn{6}{|l|}{ Safety context } \\
\hline Big objects & $3.65(1.30)$ & $3.00(1.61)$ & $2.55(1.54)$ & $2.29(1.10)$ & \\
\hline Small objects & $2.39(1.50)$ & $1.67(1.24)$ & $1.45(1.32)$ & $1.00(0.95)$ & \\
\hline \multicolumn{6}{|l|}{ Tot. objects } \\
\hline Big Objects & 7.57 (1.97) & $6.22(2.41)$ & $6.00(2.49)$ & $4.00(1.70)$ & $5.98(2.49)$ \\
\hline Small objects & $4.78(2.54)$ & $3.22(1.59)$ & $3.10(2.13)$ & $1.95(1.32)$ & $3.30(2.21)$ \\
\hline
\end{tabular}

As expected, we found stronger fear responses to CTX+ when compared with CTX - during and after acquisition. Thus, participants rated CTX + as more negative, arousing, and anxietyinducing than CTX - after both Acquisition 1 and Acquisition 2. Moreover, participants correctly reported a higher probability of US in the anxiety context than in the safety context. Importantly, physiological responses supported verbal ratings, meaning that startle response was potentiated and SCL was larger in the threat-associated office as compared to the safety office. These results are in line with our previous findings (GlotzbachSchoon et al. 2013a,b; Andreatta et al. 2015a,b) as well as with other human (Marschner et al. 2008; Lang et al. 2009; Alvarez et al. 2011; Pohlack et al. 2012) and animal (for a recent review, see Maren et al. 2013; Perusini and Fanselow 2015; Tovote et al. 2015) studies.

Regarding the "generalization" phase, we could replicate our previous study (Andreatta et al. 2015a) even if the paradigms slightly differed. Namely, we found generalization of fear responses on the explicit verbal (i.e., ratings) and physiological (i.e., SCL) levels, but generalization of safety or safety-like responses ${ }^{4}$ on the implicit behavioral level (i.e., startle response). How can we explain generalization mainly on a cognitive and explicit level? In fact, we did not instruct the change of CTX-US contingency at the beginning of the Generalization-Test Session (i.e., Day 3) and we positioned the electrodes for US delivery again on participants' forearm. Therefore, participants likely have expected the US during the test phase. In line, contingency ratings after the first test phase indicated that participants still expected the US more in CTX + than in the other contexts, and more in G-CTX than in CTX - . However, over time they might have recognized that contingencies changed, and possibly, they started expecting the US somewhere else. In line with this, a slight potentiation of startle responses to CS - has sometimes be observed (despite not always significant; Lindner et al. 2015) or a stronger amygdala activation to CS - (Phelps et al. 2004; Merz et al. 2012). Simultaneously, the third office (i.e., G-CTX), being the most ambiguous among the three, might have been the best candidate for expecting an aversive event during the test (for a broader discussion, see Andreatta et al. 2015a).

These generalization effects, however, were not unambiguous and-as expected-affected by the "time delay" between acquisition and extinction/generalization. Following up marginally significant but hypothesized effects for startle response and

${ }^{4}$ Notably, our paradigm does not allow disentangling whether the startle attenuation in the generalization context is due to safety-like responses because this context has never been associated with the aversive event or rather to generalization process of safety.
SCL, explorative analyses within the groups speak for stronger forgetting of learning conditions and also enhanced generalization of anxiety in the $15 \mathrm{~d}$ delay group compared with the $1 \mathrm{~d}$ delay group. Specifically, participants tested $24 \mathrm{~h}$ after learning (recent test) still showed enhanced startle potentiation to CTX + when compared with G-CTX and no generalization, suggesting a quite intact memory of the anxiety context. In contrast, participants tested $15 \mathrm{~d}$ after learning (remote test) showed comparable startle responses to the anxiety and generalization context, and interestingly greater physiological arousal (i.e., SCL) triggered by G-CTX. Although these results should be taken carefully, they are in line with animal studies discussed above, although the learning paradigms were different (Riccio et al. 1992; Biedenkapp and Rudy 2007). In other words, it is conceivable that both in humans and animals memory traces acquired through contextual conditioning faded out with time, and this process seems to facilitate generalization. However, it must also be considered that time delay of the generalization test did not affect participants' explicit responses (i.e., ratings). Thus, both individuals tested $24 \mathrm{~h}$ and those tested $15 \mathrm{~d}$ after acquisition session rated CTX + as more negative, arousing, and anxiogenic than CTX - , and G-CXT ratings equaled $\mathrm{CTX}+$ ratings. Considering that verbal reports reflect cognitive processes, which depend on the PFC, and that the PFC has been associated with retrieval of memory traces (Frankland and Bontempi 2005; Maren et al. 2013), it is conceivable that ratings might be less affected by context forgetting because of their strong PFC involvement.

Our results further suggest that this is likely due to forgetting of particulars of the context since our memory test revealed that participants of the recent-test group remembered more objects of the contexts and also their positions within the rooms than participants of the remote-test group. We assume that the observation that participants in the remote-test groups responded with enhanced defensive responses, i.e., enhanced startle responses, to the ambiguous generalization context is a consequence of this forgetting of contextual particulars.

Furthermore, the enhanced SCL to G-CTX in the remote-test group might be explained by a rather strong fear generalization on the explicit cognitive level in this group and a strong influence of such cognitive processes on electrodermal responses (Hamm and Weike 2005). We speculate that such interplay between cognitive and electrodermal responses may be stronger, the weaker the memory traces are, thus in the remote-test group. However, please note that these speculations are based on explorative analyses following up marginally significant effects. Thus, future studies should target greater power to come to conclusive conclusions.

Effects of "preexposure" to contexts were found for acquisition, extinction, and generalization. Regarding acquisition, we 
observed no differences throughout the acquisition phases between participants preexposed to the learning contexts versus participants preexposed to an irrelevant context, except for valence ratings. These results are overall in line with previous animal studies (Riccio et al. 1992; Biedenkapp and Rudy 2007) as well as one human context conditioning study (Tröger et al. 2012), which also found no evidence of preexposure effects on context conditioning. However, with regard to the valence ratings we observed that participants preexposed to the learning contexts distinguished less clearly between the anxiety and the safety contexts than individuals preexposed to an irrelevant context. Explorative analysis (see Supplemental Material) further indicates that the preexposure group rated the threat-associated context more negative than the threat-free context only after the second acquisition phase, whereas the no-preexposure group could already distinguish between these contexts after the first acquisition phase. Hence, at least for the valence ratings, we revealed a first hint that latent inhibition affects context conditioning in humans, as it was shown previously for cue conditioning studies in animals (Laurent and Westbrook 2009; Jordan et al. 2015) and humans (Byron Nelson and Del Carmen Sanjuan 2006; Vervliet 2013). Latent inhibition has been defined as a process, which slows down the acquisition of conditioned fear (Bouton 2004) due to preexposure to the conditioned stimulus without US administration. Interestingly, animal studies (Kraemer and Spear 1992) claimed that latent inhibition and extinction share similar mechanisms, as in both cases, the to-be associated stimulus is presented without US. Therefore, previous encounters with the to-be-trained stimulus or context may induce a safety memory trace which hinders a further association with a threatening event. Our study-to our knowledge-is the first revealing such latent inhibition effects for humans in context conditioning.

In relation to preexposure effects on extinction/generalization, we found that individuals preexposed to the training contexts showed better extinction learning on the verbal level than those who were not preexposed to these contexts. Thus, only participants of the no-preexposure group rated the anxiety context still as more negative and arousing than the safety context after extinction on the Generalization-Test Session. This lack of extinction learning on the explicit level for the no-preexposure group corroborates our previous findings (Glotzbach-Schoon et al. 2013b). Supportively, beneficial effects of preexposure on fear extinction have been previously found in both rats (Jordan et al. 2015) and humans (Vervliet 2013) despite the organisms undergoing a cued fear conditioning protocol. One might speculate that during the preexposure individuals form "safety" memory traces of these contexts (Kraemer and Spear 1992; Bouton 2004). During conditioning, a new fear memory trace will be formed for one of the contexts (Pavlov 1927), without necessarily deleting the previous traces (Bouton 2004; Milad and Quirk 2012). Finally, extinction learning can be built on these still existing "safety" memory traces and therefore is facilitated in the preexposure group (Milad and Quirk 2012).

With regard to preexposure effects on generalization, we revealed that G-CTX was rated by the preexposure group more aversive than CTX+. One possible explanation for this result is that participants still expected the painful US, but those preexposed to the contexts rather quickly assumed that the anxiety context is safe again —as discussed above-and therefore rated it as less aversive than the ambiguous generalization context. Following the idea of latent inhibition (Bouton 2004), it might be also conceivable that the first safety memory traces developed during preexposure could have been recalled by the preexposure group during the test/extinction phases, while the no-preexposure group cannot have any safe-related memory to the contexts.

In sum, our results corroborate the assumptions that when time passes, the memory traces of contextual anxiety learned through conditioning weaken, and that this process facilitates generalization. In addition, we revealed that preexposure to contexts, which later became associated with threat or safety, on a verbal, explicit level, but not on a physiological/behavioral level, retards acquisition and facilitates extinction, suggesting that latent inhibition is important for contextual conditioning.

\section{Materials and Methods}

\section{Participants}

One hundred and fifteen volunteers were recruited via advertisement on a public website and divided into four groups (for details, see Table 2 and procedure). All participants signed the informed consent before the experiment. Exclusion criteria were mental or neurological disorders as well as color blindness or hearing problems. Eight participants had to be excluded because of technical problems, one because of missing the ratings, 12 were no-responders (mean startle amplitude $<5 \mu \mathrm{V}$ ), and 10 because they had less than two startle response in one of the conditions. In the end, we considered 83 participants ( 42 females, 5 foreign, 10 left-handed individuals, and 3 ambidextrous). The study was approved by the Ethics Committee of the Medical Faculty of the University of Würzburg. Participants gained $30 €$ for their participation.

\section{Materials}

\section{Unconditioned stimulus (US)}

The aversive US was a mild painful pulse electric shock, which lasted $200 \mathrm{msec}$ with a frequency of $50 \mathrm{~Hz}$. This stimulus was

Table 2. Demographic and psychometric data of the four groups

\begin{tabular}{|c|c|c|c|c|c|}
\hline & \multicolumn{2}{|c|}{ Preexposure group } & \multicolumn{3}{|c|}{ No-preexposure group } \\
\hline & Recent test & Remote test & Recent test & Remote test & Comparisons \\
\hline Sample size & 23 & 19 & 20 & 21 & \\
\hline Gender & 12 ㅇ $110^{x}$ & $10 \bigcirc 90^{x}$ & $11 q 90^{1}$ & $9+120^{x}$ & $\chi^{2}(3, N=83)=0.71, P=0.870$ \\
\hline Not German-speaking & 0 & 0 & $1+$ t & $4+2-2$ & $\hat{\chi}^{2}(3, N=83)=9.02, P=0.029$ \\
\hline Left-handed or ambidextrous & 4 & 0 & 5 & 4 & $x^{2}(6, N=83)=7.84, P=0.250$ \\
\hline Age (SD) & 23.61 (3.49) yr & $23.37(2.52) \mathrm{yr}$ & $22.10(3.52) \mathrm{yr}$ & $23.76(3.78) \mathrm{yr}$ & $\hat{F}_{(3,79)}=1.02, P=0.387$ \\
\hline US intensity (SD) & $1.60(0.81) \mathrm{mA}$ & $1.75(1.03) \mathrm{mA}$ & $1.80(1.28) \mathrm{mA}$ & $1.74(1.22) \mathrm{mA}$ & $F_{(3,79)}=0.13, P=0.940$ \\
\hline US ratings (SD) & $4.98(0.86)$ & $4.79(1.08)$ & $5.30(1.22)$ & $5.38(1.20)$ & $F_{(3,79)}=1.29, P=0.285$ \\
\hline STAl trait (SD) & $37.22(9.15)$ & $36.58(9.55)$ & $38.25(5.95)$ & $37.33(7.43)$ & $F_{(3,79)}=0.16, P=0.924$ \\
\hline $\mathrm{BDI}(\mathrm{SD})$ & $5.78(6.47)$ & $6.37(6.46)$ & $7.95(4.64)$ & $6.52(4.95)$ & $F_{(3,79)}=0.54, P=0.655$ \\
\hline IPQ (SD) & $-0.77(2.28)$ & $-1.01(3.37)$ & $-1.45(2.38)$ & $-1.45(2.84)$ & $F_{(3,79)}=0.33, P=0.802$ \\
\hline No. of aware individuals & 14 & 17 & 15 & 15 & $\chi^{2}(3, N=83)=4.44, P=0.218$ \\
\hline No. of good remembers & 19 & 8 & 7 & 4 & $\chi^{2}(3, N=83)=19.05, P<0.001$ \\
\hline
\end{tabular}


generated by a constant current stimulator (Digitimer DS7A, Digitimer Ltd; $400 \mathrm{~V}$, maximum of $9.99 \mathrm{~mA}$ ). Two disk electrodes with a diameter of $9 \mathrm{~mm}$ diameter and spacing of $30 \mathrm{~mm}$ were used to apply the electric shock over the forearm of the dominant hand. The intensity of the US was individually assessed at the beginning of the experiment. The pain threshold procedure consisted of two ascending and two descending series of electric shocks in steps of $0.5 \mathrm{~mA}$ (for details, see Andreatta et al. 2010). Participants rated the shock on a visual analog scale ranging from 0 (no pain at all) to 10 (unbearable pain), with 4 (just noticeable pain) as the anchor for the threshold. We then calculated the mean of those intensities rated as painful and increased this value by $30 \%$ to prevent habituation. The final intensity was $1.72 \mathrm{~mA}$ $(\mathrm{SD}=1.08)$ and rated as painful $(M=5.11, \mathrm{SD}=1.10)$.

\section{Virtual reality (VR)}

The VR was based on the Source Engine (Valve Corporation) and consisted of three offices separated by a corridor and a stadium. The offices had the same square footage and a gray floor, and the view from the windows was a city (each room with a different view of the city). Importantly, the offices differed in furniture and in their arrangement (for a detailed description of the virtual environment, see Glotzbach-Schoon et al. 2013b; Andreatta et al. $2015 b$ ). The corridor was empty and had a gray floor color. In one office (anxiety context or CTX+), the painful US was delivered unpredictably, but never in the other office (safety context or CTX -). The offices were counterbalanced among participants. The third office (generalization context or G-CTX) was the exact mix of CTX + and CTX - , sharing 50\% of the CTX+ and $50 \%$ of CTX - furniture. The stadium was an open air stadium without any social stimuli. Participants could freely move on the playing field under a sunny sky. The VR environment was presented by a Z800 3D Visor head-mounted display (HDM; eMagin,) and controlled by the software CyberSession (VT+ GmbH,).

\section{Startle probes}

Stimuli for eliciting the startle response were white noise of $103 \mathrm{~dB}$ with a duration of $50 \mathrm{msec}$. The noises were binaurally presented by means of headphones.

\section{Ratings}

At different moments of the experiment, participants had to rate the valence (positive versus negative) and the arousal (calm versus exciting) of the offices as well as their anxiety level (no anxiety versus high anxiety). All visual scales ranged from 0 to 100. Moreover, participants had to indicate their contingency awareness, which is the ability to correctly indicate the association between the US and CTX. For this rating, zero on the scale indicated "no association," while 100 indicated "perfect association." For defining whether a participant was (or not) aware about US-CTX contingency, we subtracted the contingency ratings of CTXfrom those of CTX+. Individuals, who presented a difference score $\geq 70$ were defined as aware.

\section{Questionnaires}

Several questionnaires were collected to assess participants' anxiety (the German versions of the State-Trait Anxiety Inventory, STAI) (Laux et al. 1981), depression (Beck Depression Inventory, BDI) (Hautzinger et al. 2006), mood (Positive Negative Affect Scale, PANAS) (Krohne et al. 1996), or presence in the VR (Igroup Presence Questionnaire, IPQ) (Schubert et al. 2001). Statistics are reported in the Supplemental Material and values separated for the four groups are indicated in the Supplemental Table S1.

\section{Memory test}

To verify how participants recognized and remembered the anxiety and safety context, we performed a memory test shortly before the generalization phase on Generalization-Test-Day (see Supplemental Fig. S1). We divided the offices in six equal squares and within each square we chose a big (e.g., couch) and a small (e.g., a cup) object. Participants received a plan of the two rooms, where the six squares were delineated and only the windows and the door were indicated. Additionally, they received a list of the objects separated for each room. They had to indicate in which quadrant each object was located. Moreover, we performed a cluster analysis to define those individuals, who well remembered the (big) objects in both anxiety and safety contexts (see Table 1). An individual was defined as a good rememberer when he/she remembered all six big objects in each office. We found significant difference regarding the number of good remembers among the groups $\left(\chi^{2}(3, N=83)=19.05, P<0.001\right)$. Separated nonparametric tests for the test revealed that participants who were preexposed to the context could better remember the virtual rooms 24 $\mathrm{h}$ after the acquisition phase (recent test) than those participants who were preexposed to the stadium $\left(\chi^{2}(1, N=41)=9.24, P=\right.$ $0.002)$. No difference between the two groups were found when the generalization test was performed $2 \mathrm{wk}$ after the acquisition $\left(\chi^{2}(1, N=38)=3.41, P=0.065\right)$.

\section{Procedure}

The experiment consisted of a 3-d procedure (Fig. 5; Supplemental Fig. S4). On Day 1 (preexposure session), participants came in the laboratory and half of them (preexposure group) were exposed to the offices, while the other half (no-preexposure group) were exposed to the stadium. On Day 2 ( $24 \mathrm{~h}$ latter; acquisition session), all participants underwent a context conditioning protocol. On Day 3 (generalization session), all participants underwent a generalization test. Importantly, half of the preexposure and half of the no-preexposure group came into the laboratory $24 \mathrm{~h}$ after the acquisition session (recent test), whereas the other half of the two groups came $15 \mathrm{~d}$ later (remote test).

\section{Preexposure session}

The preexposure session consisted of an active and a passive phase. During the active phase, participants could freely move within the virtual environment; whereas during the passive phase, participants were guided through the virtual environment by means of prerecorded paths. The preexposure group explored both the anxiety and the safety context for $5 \mathrm{~min}$ each and then they were passively guided twice into the two offices again. The paths were the same as the ones used for the acquisition and the generalization phases to assure that participants get used to the VR. Each path started in the corridor and after 30 sec participants entered the room, where they stayed for $\sim 90 \mathrm{sec}$. The no-preexposure group actively explored the stadium for $10 \mathrm{~min}$ and then participants were passively guided through the field. After the active and passive explorations, participants had to indicate valence, arousal, and anxiety of the context and of the stadium, respectively.

\section{Acquisition session}

After the individual pain threshold was assessed, participants underwent two acquisition phases (Acquisition 1 and Acquisition 2), which were similar. Participants were told that they would have been guided into two offices and sometimes they could receive the electric shocks. We also told them that they could have caught the association between the stimuli if they would have paid attention. Each acquisition phase consisted of six trials, meaning that participants were passively guided into the anxiety context three times and into the safety context three times. The order of the trials was pseudorandomized, that is the same context was not entered more than twice in a row. One trial started in the corridor, where the participant stood in front of the door of the context he/she was going to enter. The office's door was closed and opened shortly before entering the room. The duration of the passive guidance was the same as on Day 1, namely $90 \mathrm{sec}$. Within each context, one to three startle probes were randomly delivered 


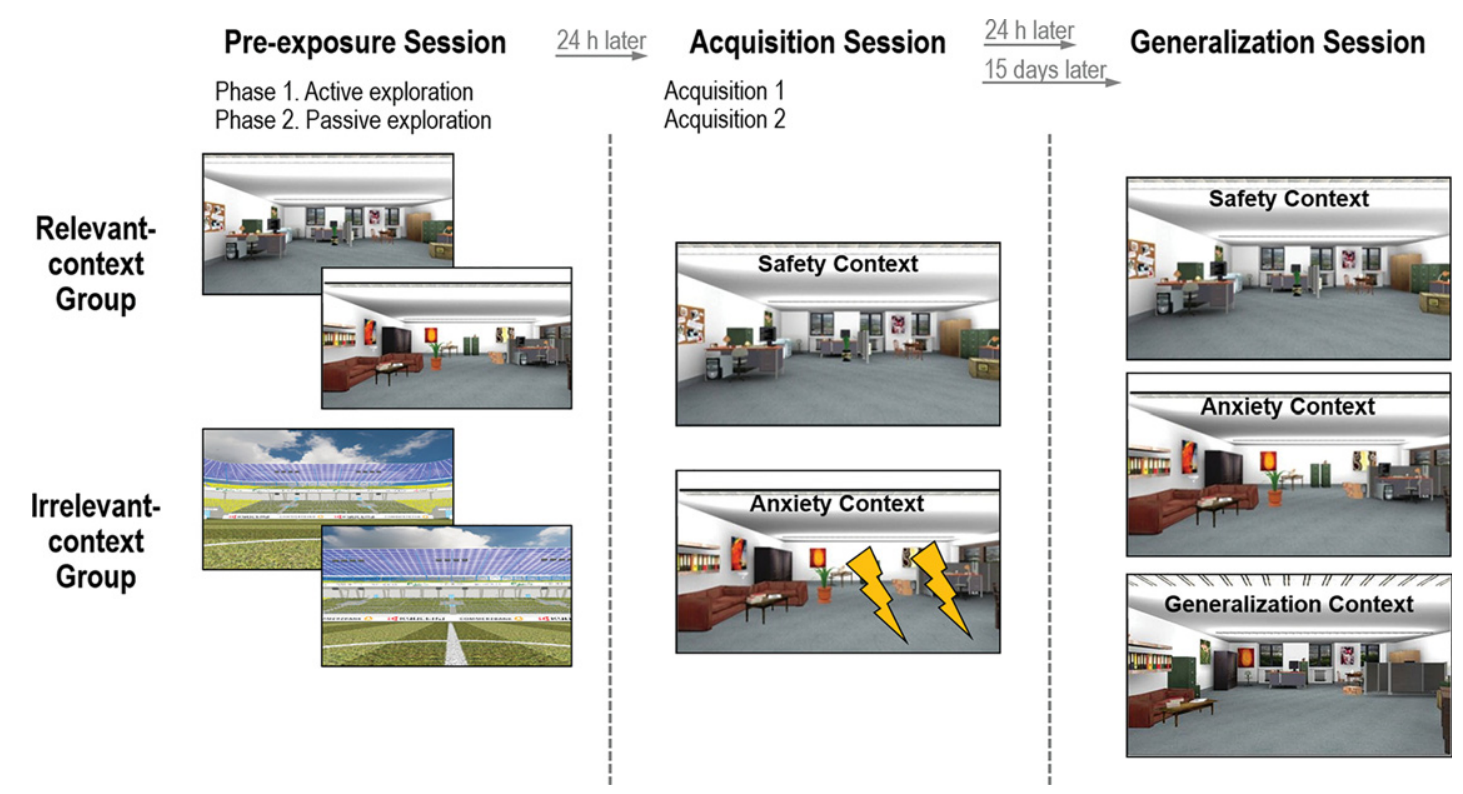

Figure 5. Design of the study. During the preexposure session, half of the participants (preexposure group) actively explored the two offices for $\sim 5$ min each, whereas the other half (no-preexposure group) actively explored a stadium for $10 \mathrm{~min}$. During the acquisition session, all participants were passively guided through the contexts on prerecorded paths and underwent a context conditioning protocol in which they received an unpredictable painful electric shock (the aversive US) in one office (anxiety context or CTX+), but never in the other office (safety context or CTX -). During generalization session, participants revisited CTX + and CTX - without receiving any US and additionally a third office (generalization context or G-CTX), which shared 50\% of $\mathrm{CTX}+$ and $50 \%$ of CTX - characteristics. Importantly, half of the preexposure group and half of the no-preexposure group returned to the laboratory $24 \mathrm{~h}$ after the acquisition phase (recent test), whereas the other half of the two groups returned 15 days after acquisition (remote test).

with a total of six startle probes per context per acquisition phase. One to three aversive USs were delivered in an unpredictable manner during the visit in the anxiety context, but never in the safety context. In total, there were six USs per acquisition phase. Importantly, the time between two startle probes, or between two USs, or between a startle probe and an US was at least 10 sec. Startle probes and USs were never delivered during the first $7 \mathrm{sec}$ and the last $7 \mathrm{sec}$ of the context visit. Finally, four startle probes were delivered in the corridor, which was the intertrial interval (ITI). The ITI lasted $\sim 30 \mathrm{sec}$, which is the time from one end of the corridor and the entrance of an office. After each acquisition phase, participants reported the valence and the arousal of the contexts as well as their anxiety level within the rooms. Additionally, participants had to indicate whether they notice any association between the US and the rooms (i.e., contingency ratings).

\section{Generalization session}

This experimental session consisted of two generalization phases, which were similar. During the generalization phases, participants were passively guided into three contexts: anxiety context, safety context, and generalization context. Each context was visited for $90 \mathrm{sec}$ three times per generalization phase and the order of the context presentations was counterbalanced among the participants. The US was never delivered, while one to three startle probes were presented during the visit to an office. At the end, there were six startle probes per context per generalization phase (altogether 36 startle probes). As in the acquisition phase, four startle probes were delivered during the ITI, which lasted $\sim 30$ sec. Similarly to the acquisition session, after each generalization session, participants were asked to rate the contexts.

\section{Data recording and data reduction}

Physiological responses were collected with a V-Amp 16 amplifier and Brain Vision Recorder Software (Version 1.03.0004, Brain Products Inc.). A $50 \mathrm{~Hz}$ notch filter and a $1000 \mathrm{~Hz}$ sampling rate were applied. The offline analyses were conducted with Brain Vision Analyzer Software (Version 2.0; Brain Products Inc).

\section{Startle response}

For the startle response, the electromyographic activity of the left orbicularis oculi muscle was continuously measured by means of two $5 \mathrm{~mm} \mathrm{Ag} / \mathrm{AgCl}$ electrodes. One electrode was placed under the pupil and the other one $\sim 1 \mathrm{~cm}$ laterally (Blumenthal et al. 2005). The ground and reference electrodes were positioned over the right and the left mastoids, respectively. For all four electrodes, the impendence was kept below $10 \mathrm{k} \Omega$ by slightly abrading and cleaning the skin with alcohol. For the offline analysis, the raw signal was first filtered with a $28 \mathrm{~Hz}$ low cutoff filter and a $500 \mathrm{~Hz}$ high cutoff filter. Then, the EMG signal was rectified and a moving average of $50 \mathrm{msec}$ was applied. The data were cut in different segments depending on the condition. Segments were registered from $50 \mathrm{msec}$ before startle probe onset and $1000 \mathrm{msec}$ after startle probe onset. The $50 \mathrm{msec}$ before probe onset were used as baseline. The startle amplitude was defined as the maximum peak within 20-150 msec after probe onset. Responses were then scored manually and trials with excessive baseline shifts $(>5 \mu \mathrm{V})$ were excluded from further analysis. We rejected $7.25 \%$ and $6.78 \%$ of the trials in the acquisition phase and in the generalization test phase, respectively. A minimum of two startle responses for each condition were required for keeping the participants in the statistical analysis. The raw signal was transformed into $z$-scores and then $T$-scores to normalize interindividual differences of this response.

\section{Skin conductance level (SCL)}

The SCL was recorded over the palm of the participants' nondominant hand by means of $10 \mathrm{~mm} \mathrm{Ag} / \mathrm{AgCl}$ electrodes. The $\mathrm{V}-\mathrm{Amp}$ system delivers a constant current of $0.5 \mathrm{~V}$, which allows us to collect the SCL. The galvanic response was offline filtered with a $1 \mathrm{~Hz}$ high cutoff filter. The signal was then segmented for the whole duration of a context (i.e., $90 \mathrm{sec}$ ). The tonic response was computed over the duration of each context excluding $10 \mathrm{sec}$ after 
US presentation. SCL data were then square-root transformed to normalize the distribution.

\section{Statistical analysis}

Data were analyzed with SPSS for Windows (Version 23, SPSS Inc.) separately for each dependent variable and each session. Separated analysis of variance (ANOVAs) were computed for valence, arousal, anxiety, and contingency ratings as well as for startle response and SCL. One-way ANOVAs for the preexposure session entailed the within-subjects factor context (CTX+, CTX-) and the between-subjects preexposure group (preexposure, no-preexposure). The ANOVAs for the acquisition session considered as within-subjects factors context (CTX+, CTX-) and phase (Acq1, Acq2) and as a between-subjects factor the preexposure group (preexposure, no-preexposure). The ANOVAs for the generalization session had context (CTX+, CTX -, G-CTX) and phase (Gen1, Gen2) as within-subjects factors and preexposure group (preexposure, no-preexposure) and test-delay (recent, remote) as between-subjects factors. The ANOVAs for the startle response presented three levels for the factor context for the analysis of the acquisition (CTX+, CTX -, ITI), and four levels for the generalization test (CTX+, CTX -, G-CTX, ITI). We used the $t$-test to compare the ratings (valence, arousal, and anxiety) of the rooms (CTX+ and CTX -) with the ratings of the stadium. For post hoc tests, we applied simple contrasts and used a Bonferroni adjustment.

For all statistical tests, the alpha $(\alpha)$ level was set at 0.05 and, if necessary, the Greenhouse-Geisser correction (GG- $\varepsilon$ ) of the degree of freedom (df) was applied. Effect sizes are reported as partial $\eta^{2}$.

\section{Competing interest statement}

P.P. and A.M. are shareholders of a commercial company that develops virtual environment research systems for empirical studies in the field of psychology, psychiatry, and psychotherapy. No further potential conflicting interests exist.

\section{Acknowledgments}

We thank Katharina Nückel and Alissa Preisner for their big help in recruiting the participants. The work was supported by the Collaborative Research Center "Fear, Anxiety, Anxiety Disorders," SFB-TRR 58 project B1 to P.P. and A.M.

\section{References}

Alvarez RP, Chen G, Bodurka J, Kaplan R, Grillon C. 2011. Phasic and sustained fear in humans elicits distinct patterns of brain activity. Neuroimage 55: 389-400.

Andreatta M, Mühlberger A, Yarali A, Gerber B, Pauli P. 2010. A rift between implicit and explicit conditioned valence in human pain relief learning. Proc Biol Sci 277: 2411-2416.

Andreatta M, Glotzbach-Schoon E, Mühlberger A, Schulz SM, Wiemer J, Pauli P. 2015a. Initial and sustained brain responses to contextual conditioned anxiety in humans. Cortex 63: 352-363.

Andreatta M, Leombruni E, Glotzbach-Schoon E, Pauli P, Mühlberger A. 2015b. Generalization of contextual fear in humans. Behav Ther 46: 583-596.

Baas JM, Nugent M, Lissek S, Pine DS, Grillon C. 2004. Fear conditioning in virtual reality contexts: a new tool for the study of anxiety. Biol Psychiatry 55: 1056-1060.

Bannerman DM, Sprengel R, Sanderson DJ, McHugh SB, Rawlins JNP, Monyer H, Seeburg PH. 2014. Hippocampal synaptic plasticity, spatial memory and anxiety. Nat Rev Neurosci 15: 181-192.

Biedenkapp JC, Rudy JW. 2007. Context preexposure prevents forgetting of a contextual fear memory: implication for regional changes in brain activation patterns associated with recent and remote memory tests. Learn Mem 14: 200-203.

Blumenthal TD, Cuthbert BN, Filion DL, Hackley S, Lipp OV, van Boxtel A. 2005. Committee report: guidelines for human startle eyeblink electromyographic studies. Psychophysiology 42: 1-15.
Bouton ME. 2004. Context and behavioral processes in extinction. Learn Mem 11: $485-494$.

Byron Nelson J, Del Carmen Sanjuan M. 2006. A context-specific latent inhibition effect in a human conditioned suppression task. Q J Exp Psychol 59: 1003-1020.

Davis M, Walker DL, Miles L, Grillon C. 2010. Phasic vs sustained fear in rats and humans: role of the extended amygdala in fear vs anxiety. Neuropsychopharmacology 35: 105-135.

Fanselow MS. 2010. From contextual fear to a dynamic view of memory systems. Trends Cogn Sci 14: 7-15.

Fonteyne R, Vervliet B, Hermans D, Baeyens F, Vansteenwegen D. 2010. Exposure to the context and removing the unpredictability of the US: two methods to reduce contextual anxiety compared. Biol Psychol 85: $361-369$.

Frankland PW, Bontempi B. 2005. The organization of recent and remote memories. Nat Rev Neurosci 6: 119-130.

Fullana MA, Harrison BJ, Soriano-Mas C, Vervliet B, Cardoner N, Àvila-Parcet A, Radua J. 2016. Neural signatures of human fear conditioning: an updated and extended meta-analysis of fMRI studies. Mol Psychiatry 21: 500-508.

Glotzbach-Schoon E, Andreatta M, Mühlberger A, Pauli P. 2013a. Context conditioning in virtual reality as a model for pathological anxiety. e-Neuroforum 4: $63-70$.

Glotzbach-Schoon E, Tadda R, Andreatta M, Tröger C, Ewald H, Grillon C, Pauli P, Mühlberger A. 2013b. Enhanced discrimination between threatening and safe contexts in high-anxious individuals. Biol Psychol 93: $159-166$

Grillon C, Baas JM, Cornwell B, Johnson L. 2006. Context conditioning and behavioral avoidance in a virtual reality environment: effect of predictability. Biol Psychiatry 60: 752-759.

Hamm AO, Weike AI. 2005. The neuropsychology of fear learning and fear regulation. Int J Psychophysiol 57: 5-14.

Hautzinger M, Keller F, Kühner C. 2006. BDI-II. Beck Depressions Inventar Revision - Manual. Harcourt Test Services, Frankfurt.

Huff N, Alba Hernandez J, Fecteau M, Zielinski D, Brady R, LaBar KS. 2011. Revealing context-specific conditioned fear memories with full immersion virtual reality. Front Behav Neurosci 5: 75.

Jordan WP, Todd TP, Bucci DJ, Leaton RN. 2015. Habituation, latent inhibition, and extinction. Learn Behav 43: 143-152.

Kalisch R, Korenfeld E, Stephan KE, Weiskopf N, Seymour B, Dolan RJ 2006. Context-dependent human extinction memory is mediated by a ventromedial prefrontal and hippocampal network. J Neurosci 26: 9503-9511.

Kraemer P, Spear N. 1992. The effect of nonreinforced stimulus exposure on the strength of a conditioned taste aversion as a function of retention interval: do latent inhibition and extinction involve a shared process? Anim Learn Behav 20: 1-7.

Krohne HW, Egloff B, Kohmann CW, Tausch A. 1996. Untersuchungen mit einer deutschen Version der "Positive and Negative Affect Schedule" (PANAS). Diagnostica 42: 139-156.

LaBar KS, Phelps EA. 2005. Reinstatement of conditioned fear in humans is context dependent and impaired in amnesia. Behav Neurosci 119: $677-686$.

Lang S, Kroll A, Lipinski SJ, Wessa M, Ridder S, Christmann C, Schad LR, Flor H. 2009. Context conditioning and extinction in humans: differential contribution of the hippocampus, amygdala and prefrontal cortex. Eur J Neurosci 29: 823-832.

Laurent V, Westbrook RF. 2009. Infusion of the NMDA receptor antagonist, DL-APV, into the basolateral amygdala disrupts learning to fear a novel and a familiar context as well as relearning to fear an extinguished context. Learn Mem 16: 96-105.

Laux L, Glanzmann P, Schaffner P, Spielberger CD. 1981. Das State-Trait Angstinventar. Beltz Test, Weinheim.

Lindner K, Neubert J, Pfannmöller J, Lotze M, Hamm AO, Wendt J. 2015. Fear-potentiated startle processing in humans: parallel fMRI and orbicularis EMG assessment during cue conditioning and extinction. Int J Psychophysiol 98: 535-545.

Maren S, Phan KL, Liberzon I. 2013. The contextual brain: implications for fear conditioning, extinction and psychopathology. Nat Rev Neurosci 14: $417-428$.

Marschner A, Kalisch R, Vervliet B, Vansteenwegen D, Büchel C. 2008. Dissociable roles for the hippocampus and the amygdala in human cued versus context fear conditioning. J Neurosci 28: 9030-9036.

Mechias ML, Etkin A, Kalisch R. 2010. A meta-analysis of instructed fear studies: implications for conscious appraisal of threat. Neuroimage $\mathbf{4 9}$ : 1760-1768.

Merz CJ, Tabbert K, Schweckendiek J, Klucken T, Vaitl D, Stark R, Wolf OT. 2012. Neuronal correlates of extinction learning are modulated by sex hormones. Soc Cogn Affect Neurosci 7: 819-830.

Milad MR, Quirk GJ. 2012. Fear extinction as a model for translational neuroscience: ten years of progress. Annu Rev Psychol 63: 129-151. 
O'Keefe J, Dostrovsky J. 1971. The hippocampus as a spatial map. Preliminary evidence from unit activity in the freely-moving rat. Brain Res 34: 171-175.

Pavlov IP. 1927. Conditioned reflexes: An investigation of the physiological activity of the cerebral cortex. Oxford University Press, London.

Perusini JN, Fanselow MS. 2015. Neurobehavioral perspectives on the distinction between fear and anxiety. Learn Mem 22: 417-425.

Phelps EA, Delgado MR, Nearine KI, LeDoux JE. 2004. Extinction learning in humans: role of the amygdala and vmPFC. Neuron 43: 897-905.

Pohlack ST, Nees F, Ruttorf M, Schad LR, Flor H. 2012. Activation of the ventral striatum during aversive contextual conditioning in humans. Biol Psychol 91: 74-80.

Rasch B, Büchel C, Gais S, Born J. 2007. Odor cues during slow-wave sleep prompt declarative memory consolidation. Science 315: 1426-1429.

Riccio DC, Ackil JK, Burch-Vernon A. 1992. Forgetting of stimulus attributes: methodological implications for assessing associative phenomena. Psychol Bull 112: 433-445.

Richter-Levin G. 2004. The amygdala, the hippocampus, and emotional modulation of memory. Neuroscientist 10: 31-39.

Rudy JW. 2009. Context representations, context functions, and the parahippocampal-hippocampal system. Learn Mem 16: 573-585.
Sanchez-Vives MV, Slater M. 2005. From presence to consciousness through virtual reality. Nat Rev Neurosci 6: 332-339.

Schiller D, Eichenbaum H, Buffalo EA, Davachi L, Foster DJ, Leutgeb S, Ranganath C. 2015. Memory and space: towards an understanding of the cognitive map. J Neurosci 35: 13904-13911.

Schubert T, Friedmann F, Regenbrecht H. 2001. The experience of presence: factor analytic insights. Presence: Teleoperators and Virtual Environments 10: $266-281$.

Squire LR. 2004. Memory systems of the brain: a brief history and current perspective. Neurobiol Learn Mem 82: 171-177.

Squire LR, Zola-Morgan S. 1991. The medial temporal lobe memory system. Science 253: $1380-1386$.

Tovote P, Fadok JP, Luthi A. 2015. Neuronal circuits for fear and anxiety. Nat Rev Neurosci 16: 317-331.

Tröger C, Ewald H, Glotzbach E, Pauli P, Mühlberger A. 2012. Does pre-exposure inhibit fear context conditioning? A Virtual Reality Study. J Neural Transm 119: 709-719.

Vervliet B. 2013. Latent inhibition speeds up but weakens the extinction of conditioned fear in humans. J Psychol Psychother $\mathbf{S} 7$ doi: 10.4172/21610487.S7-002.

Received September 23, 2016; accepted in revised form October 14, 2016. 


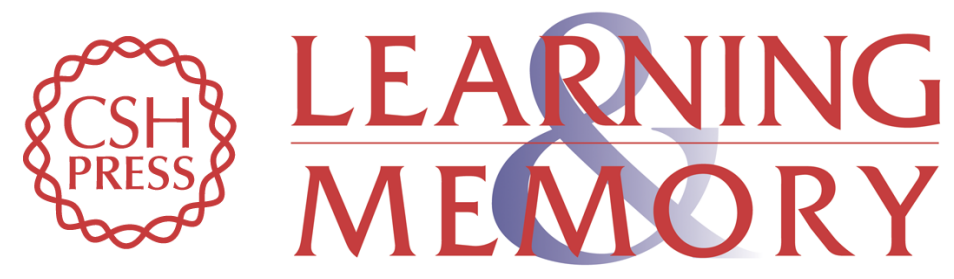

\section{Effects of context preexposure and delay until anxiety retrieval on generalization of contextual anxiety}

Marta Andreatta, Dorothea Neueder, Evelyn Glotzbach-Schoon, et al.

Learn. Mem. 2017, 24:

Access the most recent version at doi:10.1101/Im.044073.116

\section{Supplemental http://learnmem.cshlp.org/content/suppl/2016/12/08/24.1.43.DC1 Material}

References This article cites 48 articles, 10 of which can be accessed free at: http://learnmem.cshlp.org/content/24/1/43.full.html\#ref-list-1

Creative This article, published in Learning \& Memory, is available under a Creative Commons Commons License (Attribution-NonCommercial 4.0 International), as described at License http://creativecommons.org/licenses/by-nc/4.0/.

Email Alerting Receive free email alerts when new articles cite this article - sign up in the box at the Service top right corner of the article or click here. 